\title{
Analisis Penurunan Unsur Fe Pada Pelumas Final Drive RH dan LH Unit HD 785-7 di PT. Petrosea .Tbk Site Gunung Bayan Kalimantan Timur dengan Proses Kidney loop
}

\author{
Randis $^{1)}$, Sidi Na'ali ${ }^{2)}$ \\ 1,2) Teknik Mesin Alat Berat, Politeknik Negeri Balikpapan \\ e-mail : randis@poltekba.ac.id
}

\begin{abstract}
The purpose of this study is to determine lubricants contamination reduction of final drive LH and $R H$ in the ppm unit by using the kidney loop process. The kidney loop process of systems are used for circulating lubricants oil from the thoughtful system to the filtration (screening), therefore hopefully this process is able to reduce the contamination that occurs in the lubricant. Data is collected in PT. Petrosea.Tbk Site Gunung Bayan East Kalimantan by comparing between the result of contamination that occurred in the final drive lubricant sample testing LH and RH unit HD 785-7 without treatment and contamination lubricant after the process of kidney loop filtration. The results obtained that $42 \%$ reduction particle level on the final drive lubricant $R H$ occurred, or there is declining lubricant contamination element Fe on the final drive RH from 111 ppm to 54 ppm. Whereas, on the final drive lubricant LH occurred 58\% reduction, or there is decreasing lubricant contamination Fe element final drive LH from 131 ppm to 55 ppm.
\end{abstract}

Keywords: kidney loop, contamination, lubricants

\begin{abstract}
Abstrak
Tujuan dari penelitian ini yaitu untuk mengetahui penurunan kontaminasi pelumas final drive LH dan RH dalam satuan ppm dengan menggunakan proses kidney loop. Proses kidney loop pada sistem digunakan untuk mensirkulasikan minyak pelumas dari dalam sistem menuju filterasi (penyaringan) sehingga diharapkan proses ini mampu mengurangi kontaminasi yang terjadi pada pelumas. Pengambilan data dilakukan di PT. Petrosea .Tbk Site Gunung Bayan Kalimantan timur dengan membandingkan hasil kontaminasi yang terjadi pada pengujian sampel pelumas final drive LH dan RH unit HD 785-7 tanpa perlakuan dan kontaminasi pelumas setelah dilakukan proses filtrasi dengan kidney loop. Hasil yang diperoleh, terjadi reduksi tingkat partikel sebesar $42 \%$ pada pelumas final drive RH, atau terjadi penurunan kontaminasi unsur Fe pada pelumas final drive RH dari 111 ppm ke 54 ppm. Sedangkan pada pelumas final drive LH terjadi reduksi sebesar 58\%, atau terjadi penurunan kontaminasi unsur Fe pada pelumas final drive LH dari 131 ppm ke 55 ppm.
\end{abstract}

Kata kunci : kidney loop, kontaminasi, pelumas

\section{Pendahuluan}

Minyak pelumas merupakan salah satu hal terpenting dalam proses kerja unit yang berfungsi sebagai bahan pelumas, pendingin dan penyekat. Pelumas juga merupakan salah satu hal terpenting yang sangat rentan terhadap kerusakan berupa kontaminasi partikel sehingga dapat mempengaruhi kualitas oli itu sendiri. Dalam penggunaannya tak dapat dipungkiri minyak pelumas pasti memiliki kontaminasi, namun kontaminasi disini harus dapat dikendalikan /dikontrol sehingga dapat menjaga kualitas oli itu sendiri serta menambah waktu pemakaian (life time) oli tersebut [4].

Minyak pelumas (Oli) yang layak digunakan adalah yang mampu menjaga kinerja mesin tetap prima, memiliki kemampuan pelumasan yang baik, peredam dan perapat untuk menghindari keausan serta memiliki standar ISO yang aman dan disarankan sehingga kontaminasi yang terjadi dapat diminimalisir [4]. Kontaminasi yang terjadi pada minyak pelumas dapat menyebabkan terjadinya kerusakan dini pada berbagai komponen mesin. Kontaminasi pada pelumas juga dapat 
menyebabkan pengantian pelumas yang lebih cepat diluar penjadwalan yang telah diatur sebelumnya [1]. Hal ini mengakibatkan terjadinya penurunan efesisensi dan efektifitas kerja unit sehingga memungkingkan tidak tercapainya target produksi perusahaan.

Dari data yang dikumpulkan, sebagian besar kerusakan tidak wajar ini didapati karena pengaruh kontaminasi oli dalam sistem yang berlebih. Berdasarkan hal tersebut dibuatlah Kidneyloop yang berfungsi untuk mengurangi kontaminasi yang terjadi pada pelumas dengan system kerja yang menyerupai ginjal manusia (filterisasi). Tujuan penelitian ini adalah mengetahui seberapa besar penurunan tingkat kontaminasi kandungan $\mathrm{Fe}$ pada pelumas final drive $\mathrm{RH}$ dan $\mathrm{LH}$ pada unit HD 785-7 di PT. Petrosea .Tbk Site Gunung Bayan Kalimantan timur sehingga diharapkan dan dipastikan life time oli sesuai dengan standar sehingga dapat mengurangi biaya maintenance dan meminimalisir terjadinya kerusakan terhadap komponen uni sebelum waktunya.

\section{Kajian Pustaka}

\section{Kontaminasi}

Kontaminasi merupakan berbagai macam material asing di dalam sistem yang bukan merupakan bagian dari sistem tersebut. Kontaminasi merupakan salah satu penyebab banyaknya kerusakan yang terjadi pada unit alat berat terutama pada engine, hidrolik dan trans misi. Untuk menanggulangi kontaminasi pada suatu system, maka dilakukan pengendalian kontaminasi yaitu suatu program pengontrolan masuknya kontaminasi ke dalam sistem.

Hal ini bertujuan untuk menjaga kinerja unit tetap prima sehingga target produksi dapat tercapai sesuai dengan waktu yang ditentukan. Pengendalian kontaminasi sangat penting diterapkan dalam melakukan perawatan unit demi menjaga kondisi kinerja unit yang prima.
Hal ini sering sekali terabaikan karena tidak dapat terlihat dengan kasat mata sehingga kita sering tidak menyadarinya.

Jenis kontaminasi yang terjadi pada suatu sistem dapat terjadi akibat adanya partikel luar yang masuk kedalam sistem sehingga sistem terkontaminasi. Adapun jenis partikel tersebut antara lain kotoran, partikel bekas pengelasan, Cat, Serpihan plastic, Partikel akibat keausan logam, Debu rokok, Gemuk (grease), Material yang timbul akibat oksidasi oli (jelaga).

Jenis kontaminasi juga dapat dibedakan atas contaminant yang masih bisa dilihat oleh mata yaitu $\geq 40$ mikron dan yang tak dapat dilihat $\leq 40$ mikron. Meskipun partikel tidak dapat dilihat namun masih dapat merusak sistem.

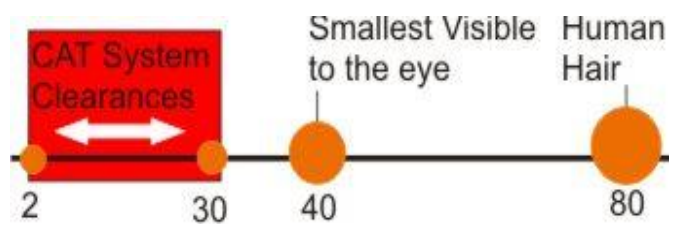

Gambar 2 : Jenis-jenis kontaminasi[1].

Clearance pada komponen berkisar antara 2-30 mikron. Clearance ini begitu kecil bila dibandingkan dengan ukuran rambut manusia (80 mikron) dan clearance sebesar ini cenderung tidak terlihat karena kemampuan mata manusia untuk melihat hanya terbatas hingga 40 mikron. Satu mikron sama dengan sepersejuta meter, sebagai perbandingan 100 microns $=$ sebutir garam, 80 microns $=$ diameter rambut manusia[1].

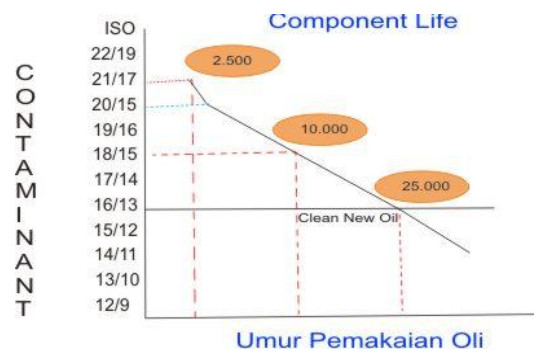

Gambar 3. Component life vs umur pemakaian oli [1] 
Dari gambar 3 diperlihatkan bahwa umur komponen sangat berpengaruh terhadap kontaminasi yang terjadi pada oli dalam sistem. Semakin besar nilai ISO pada sistem akan semakin memendekan umur komponen namun jika oli dijaga pada nilai $18 / 15$ atau dibawahnya maka usia komponen akan semakin meningkat umur pemakaiannya[1].

\section{Kidney loop}

Kidneyloop terdiri dari dua kata yaitu Kidney (Ginjal) dan Loop (putaran). Merupakan sebuah alat yang berfungsi mereduksi partikel pada pelumas dengan cara mensirkulasikan dan memfilterasi pelumas secara berurutan melalui Differential atau Final drive $R H$ dan $L H$, pompa diafragma, magnetic screen, filter 4 micron dan 7 micron kemudian kembali ke Differential atau Final drive $R H$ dan $L H$.

Serupa dengan ginjal manusia Kidney loop digunakan juga untuk menyaring oli baru masuk ke dalam storage. Kidneyloop dibuat dengan dengan tujuan untuk meminimalisir kontaminasi pada sistem pelumasan, juga menjaga kualitas kinerja unit dalam kondisi prima. Berdasarkan kegunaannya tersebut Kidneyloop mampu menjaga life time dari sebuah komponenkomponen mesin karena mengurangi adanya kontaminasi pada sistem.

Kidneyloop merupakan alat sederhana yang hanya memiliki beberapa komponen utama. Kegunaan komponenkomponen ini tentunya demi menunjang kerja sirkulasi oli dalam meminimalisir kontaminasi yang terjadi di dalam sistem. berikut merupakan komponen-komponen sederhana pada Kidneyloop: Pompa diafragma, Filter, Magnetic Screen,Hose, dan Connector[7].

\section{Metode Penelitian}

Pengambilan data dilakukan di PT. Petrosea. Tbk site Gunung Bayan. Pengambilan data dilakukan dengan kondisi pelumas normal (tanpa kidney loop) dan pengambilan data untuk pelumas yang di lakukan kidney loop. Pengujian ini di lakukan untuk pelumas pada pelumas final drive $\mathrm{RH}$ dan final drive $\mathrm{LH}$.

Prosedur penelitian ini ditunjukkan pada gambar dibawah ini:

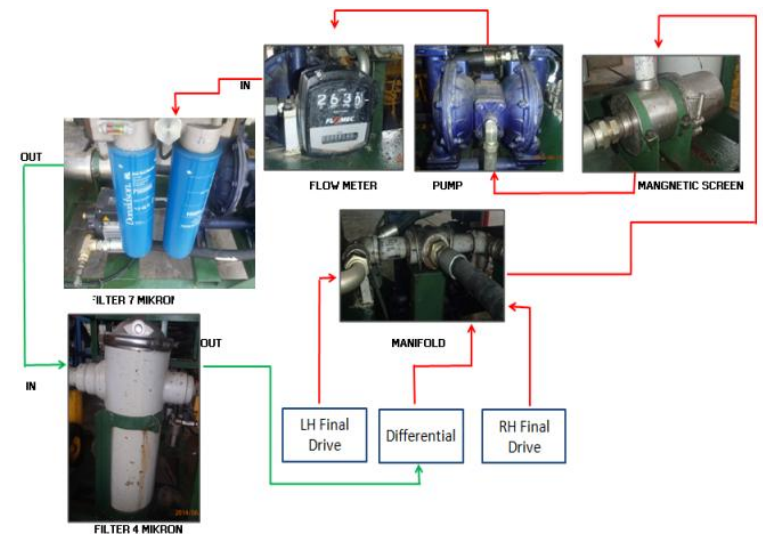

Sebelum dilakukan kidney loop, minyak pelumas minyak pelumas di dalam final drive $\mathrm{RH}$ dan $\mathrm{LH}$ di ambil sampelnya untuk dilakukan pengukuran kontaminasi unsur yang terkandung didalamnya, selanjutnya magnetig plug juga diperiksa di range mana kontaminasi pelumas yang terjadi[5]. Selanjutnya sampel pelumas dari final drive $\mathrm{RH}$ dan $\mathrm{LH}$ setelah proses kidney loop juga diambil untuk sampel pengujian pengukuran kontaminasi logam yang terkandung didalamnya. Adapun prosedur dari kidney loop adalah sebagai berikut:

a. Pasang Transduser pada Differential Housing Breather, sambungkan dengan Hose angin supaya Differential Housing menjadi Vakuum.

b. Pasangkan Connector di LH Final Drive, RH Final Drive dan Differential Housing (Magnetic Plug dan Drain Plug).

c. Sambungkan hose A dengan connector RH Final Drive, Hose B dengan Drain Plug Differential Housing, Hose C dengan LH Final Drive dan Hose D dengan Magnetic Plug Differential Housing.

d. Reset Flowmeter keposisi 0000 dengan memutar Knob secara CW (Clock Wise).

Setelah tool Kidney loop sudah siap, bisa dimulai proses Kidney loop. Tool 
e. Kidney loop mempunyai dua system pemompaan Oli, dengan Diaphragm Pump dan Electric Pump.

f. Selanjutnya proses monitoring (particle counter) dengan memasang transduser pada differential housing Breather, kemudian Hose angin juga disambungkan supaya Differential Housing menjadi Vakuum. Pasangkan Connector di LH Final Drive, RH Final Drive dan Differential Housing (Magnetic Plug dan Drain Plug).

g. Sambungkan hose A dengan connector RH Final Drive, Hose B dengan Drain Plug Differential Housing, Hose C dengan LH Final Drive dan Hose D dengan Magnetic Plug Differential Housing.

h. Reset Flowmeter keposisi 0000 dengan memutar Knob secara CW (Clock Wise). Setelah tool Kidney loop sudah siap, bisa dimulai proses Kidney loop. Tool Kidney loop mempunyai dua system pemompaan Oli, dengan Diaphragm Pump dan Electric Pump. Diaphragm Pump Tutup Inlet Valve ke Electric Pump, sambungkan Hose angin dengan Connector Diaphragm Pump[3].

Setelah proses kidney loop dilakukan, sampel pelumas final drive $\mathrm{RH}$ dan $\mathrm{LH}$ diambil dan disimpan kedalam botol sampel dengan menggunakan peralatan Schedule Oil Sampling (SOS) berupa Selang kecil, Vacum Pump, dan Botol SOS. Sampel ini selanjutnya akan dikirim dan diuji di SOSLAB[2].

\section{Hasil Penelitian}

Data Trending S.O.S before and after kidneyloop merupakan data yang di dapat dari laboratorium PT. Trakindo Utama.Tbk kota Balikpapan dari unit-unit perusahaan PT.PETROSEA.Tbk Site Gunung Bayan[6]. Data yang diperoleh ini bertujuan untuk dapat mengetahui kandungan-kandungan yang ada di dalam oli/pelumas dari final drive dan differential unit Komatsu HD 785-7, berikut merupakan data S.O.S nya:

Berdasarkan oli sampel yang diuji, didapatkan hasil berupa trending SOS Final Drive $R H$ dan LH yang menggambarkan tingkat keausan material pada pelumas terhadap standar maksimum yang diizinkan. Hasil perbandingan pengujian kontaminasi oli tersebut disajikan kedalam Gambar 4.1 dan 4.2.

\section{a. Reduksi Fe Pada Final Drive RH}

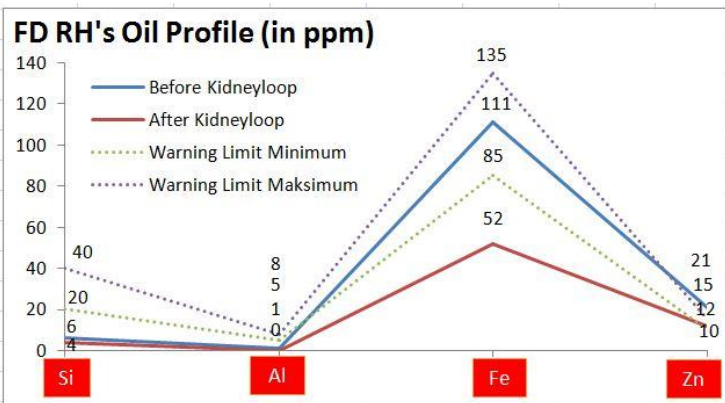

Grafik 4.1 Grafik Trend hasil SOS Final drive $R H$

Pada grafik 4.1 nilai Limit minimum dan maksimum partikel yang diizinkan pada kandungan pelumas yaitu sebesar $\mathrm{Fe}=85-135 \mathrm{ppm}$ (Grafik hijau dan ungu). Dari hasil pengujian laboratorium menggunakan sampel normal (tanpa kidneyloop) didapatkan kadar $\mathrm{Fe}=111$ ppm (Grafik Biru). Sementara itu untuk hasil uji sampel oli dengan kidneyloop didapatkan kadar $\mathrm{Fe}=52$ ppm (Grafik Merah). Berdasarkan gambar 4.5 Trend hasil SOS pada Final drive $R H$ diatas, maka ada penurunan kadar partikel $\mathrm{Fe}$ rata-rata sebesar:

$$
\begin{aligned}
P & =1-\frac{\sum_{\text {partikel Fedengan kidneyloop }}}{\sum_{\text {partikel Fe tanpa kidneyloop }}} \times 100 \% \\
& =1-\frac{52}{111} x 100 \%=53 \%
\end{aligned}
$$




\section{b. Reduksi Fe Pada Final Drive LH}

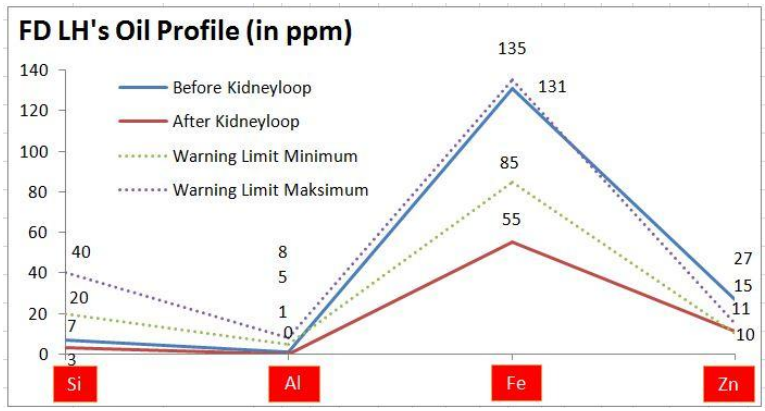

Grafik 4.2 Grafik Trend hasil SOS Final drive $L H$

Pada grafik 4.2 besarnya nilai limit minimum dan maksimum partikel yang diizinkan pada kandungan pelumas yaitu sebesar $\mathrm{Fe}=85-135$ ppm (Grafik hijau dan ungu). Dari hasil pengujian laboratorium menggunakan sampel normal (tanpa kidneyloop) didapatkan kadar $\mathrm{Fe}=131 \mathrm{ppm}$ (Grafik Biru) hal ini menunjukkan kadar $\mathrm{Fe}$ yang terkandung dalam pelumas sudah hamper mencapai batas maksimum yang diizinkan. Sementara itu untuk hasil uji sampel oli dengan kidneyloop didapatkan kadar $\mathrm{Fe}=52$ ppm (Grafik Merah). Berdasarkan grafik 4.2 Trend hasil SOS pada Final drive $L H$ diatas, maka ada penurunan kadar partikel $\mathrm{Fe}$ rata-rata sebesar:

$$
\begin{aligned}
P & =1-\frac{\sum_{\text {partikel dengan kidneyloop }}}{\sum_{\text {partikel tanpa kidneyloop }}} \times 100 \% \\
& =1-\frac{55}{131} \times 100 \%=58 \% .
\end{aligned}
$$

Dari kedua hasil grafik di atas dapat disimpulkan bahwa kidneyloop mampu mereduksi partikel material menjadi lebih sedikit, salah satu presentase reduksi partikel terbesar terjadi pada nilai $\mathrm{Fe}$ yaitu sebesar 131 ppm menjadi 52 ppm. Secara keseluruhan pada Final Drive LH reduksi yang tercapai adalah sebesar $58 \%$. Presentase pada Final Drive LH menunjukan bahwa efektifitas kidneyloop di nilai mampu dan tepat dalam penggunaannya sebagai alat Filterasi oli demi memaksimalkan pemakaian umur oli pada Final Drive.

\section{Kesimpulan}

Berdasarkan hasil penelitian di lapangan menggunakan kidneyloop terhadap umur pemakaian oli Final Drive unit HD 785-7 di PT. Petrosea .Tbk Site Gunung Bayan Project, dapat disimpulkan bahwa :

1. Pengaruh filterasi oli final drive dengan menggunakan Kidneyloop memiliki kemampuan mereduksi tingkat partikel sebesar :

\begin{tabular}{|l|l|l|}
\hline No & Penyaringan pada & Reduksi Fe \\
\hline 1 & Final Drive $R H$ & $53 \%$ \\
\hline 2 & Final Drive $L H$ & $58 \%$ \\
\hline
\end{tabular}

Reduksi yang terjadi tersebut menurunkan jumlah keausan terhadap partikel metal pada komponen sebesar :

\begin{tabular}{|l|l|l|l|}
\hline No & Komponen & $\begin{array}{l}\text { Sebelum } \\
\text { Filterasi }\end{array}$ & $\begin{array}{l}\text { Sesudah } \\
\text { Filterasi }\end{array}$ \\
\hline 1 & Final Drive $R H$ & 111 & 52 \\
\hline 2 & Final Drive LH & 131 & 55 \\
\hline
\end{tabular}

Penurunan partikel $\mathrm{Fe}$ tersebut mempengaruhi kinerja pelumasan pada komponen final drive dalam menjalankan fungsi-fungsi oli secara optimal dan membentuk oil film yang akan bekerja memberikan complete separation of moving surface sehingga life time komponen tersebut dapat tercapai sesuai dengan standar life time yang ditentukan.

2. Penyebab kenaikan nilai partikel Fe disebabkan oleh adanya Friction yang terus-menerus terjadi pada proses kerja komponen final drive.

\section{Saran}

Dari kesimpulan di atas, maka sangat memungkinkan untuk mengembangkan penelitian ini lebih lanjut:

a. Penilitian lebih lanjut dapat melakukan analisa berupa prediksi kerusakan komponen mesin dengan melakukan pengujian pada minyak pelumas pada system. 
b. Penelitian juga dapat dikembangkan dengan melakukan pengujian pada minyak pelumas pada engine, differensial dan system hidrolik pada unit.

\section{Daftar Pustaka}

Trakindo. (2003). Contamination control of Training Center. Caterpillar basic training,Cileungsi.

Trakindo, (2003). Schedule Oil Sampling. Jakarta.

Petrosea. (2000). Work Instruction of kidney loop.
PT. Petrosea. Tbk (2000). Basic knowledge of engine oil. Training Center Department

Trakindo. (2003). Magnetic Plug Rating. Maintenance Division

Database PT. Petrosea. Tbk site Project Gunung bayan

Dory S, Hansen T. (2002), Contamination Control Program. Diakses 10 Januari 2016. Available from: http://machinery lubrication.com/Read/497/ mobileequipment contamination. 